\title{
Sistem Monitoring Suhu Air pada Kolam Benih Ikan Koi Berbasis Internet of Things
}

\section{The Monitoring System for Water Temperature at Koi Fishponds Based on Internet of Things}

\author{
Slamet Indriyanto ${ }^{1 *}$, Fikra Titan Syifa ${ }^{2}$, Hanif Aditya Permana ${ }^{3}$ \\ 1,2,3 Institut Teknologi Telkom Purwokerto \\ Jl. D.I. Panjaitan No.128 Purwokerto, 0281-641629 \\ slamet@ittelkom-pwt.ac.id ${ }^{1 *}$, fikra@ittelkom-pwt.ac.id ${ }^{2}, 16201080 @$ ittelkom-pwt.ac.id $^{3}$
}

\begin{abstract}
Abstrak - Ikan koi merupakan salah satu jenis ikan hias yang banyak dipelihara oleh masyarakat karena memiliki bentuk serta corak warna yang indah. Pertumbuhan benih ikan koi sangat dipengaruhi oleh faktor lingkungan, diantaranya adalah suhu air kolam. Suhu air untuk pertumbuhan, selera makan, dan berat benih ikan koi berada pada $25^{\circ} \mathrm{C}-27^{\circ} \mathrm{C}$. Tujuan dari penelitian ini adalah merancang dan membuat sistem monitoring suhu pada kolam benih ikan koi berbasis IoT. Hardware yang digunakan yaitu development board NodeMCU ESP8266, sensor suhu DS18B20, Relay, dan Water Heater. Sistem yang dibuat dapat memantau suhu air kolam dan menstabilkan suhu kolam secara otomatis menggunakan heater. Dari hasil pengujian sensor suhu yang digunakan didapatkan rata-rata error pada kondisi dingin sebesar 3,426 \%, rata-rata error pada kondisi normal sebesar $1,778 \%$ dan rata-rata error pada kondisi panas sebesar 1,546\%. Angka ini menunjukkan akurasi yang baik untuk pengukuran sensor.
\end{abstract}

Kata Kunci: Sistem monitoring, ikan koi, sensor suhu DS18B20, NodeMCU ESP8266, IoT.

\begin{abstract}
Koi fish is a type of ornamental fish that is maintained by many people because it has a beautiful shape and color pattern. Koi fish seed growth is strongly influenced by environmental factors, such as the temperature of the pool water. Water temperature for growth, optimum appetite, and weight gain of koi fish are in the range of $25^{\circ} \mathrm{C}-27^{\circ} \mathrm{C}$. The purpose of this research is to design the temperature monitoring system in the koi fishpond based on IoT. The hardware consists of the development board NodeMCU ESP8266, temperature sensor DS18B20, relay, and water heater. The system was able to monitor the water temperature of the pond and to stabilize it using the heater automatically. The results obtained the average error in the cold condition $3.426 \%$, the average error under normal condition $1.778 \%$, and the average error in hot condition $1.546 \%$. These values show the accuracy of the sensor's measurement.
\end{abstract}

Keywords: Monitoring system, koi, temperature sensor DS18B20, NodeMCU ESP8266, IoT.

\section{Pendahuluan}

Ikan hias merupakan jenis ikan yang dipelihara untuk mempercantik suatu taman ataupun ruang tamu namun tidak untuk dikonsumsi. Keberadaan ikan hias didalam rumah menjadi salah satu hiburan tersendiri bagi masyarakat. Salah satu ikan hias air tawar yang banyak diminati oleh

TELKA, Vol.6, No.1, Mei 2020, pp. 10 19

ISSN (e): 2540-9123

ISSN (p): 2502-1982 
masyarakat diantaranya yaitu ikan koi. Ikan koi banyak diminati karena keindahan bentuk badan serta warnanya, dan dipercaya membawa keuntungan oleh para pecinta koi [1].

Beberapa daerah di Indonesia saat ini memiliki potensi yang besar sebagai penghasil benih ikan koi [1]. Benih ikan adalah anakan ikan yang memiliki ukuran tertentu yang digunakan sebagai bibit pada kegiatan budidaya ikan. Pertumbuhan benih ikan koi sangat tergantung oleh beberapa faktor, seperti jenis ikan, sifat genetis, pakan, kepadatan tebar benih ikan, dan faktor lingkungan. Faktor lingkungan yang mempengaruhi diantaranya adalah suhu air. Emaliana dalam penelitiannya [2] menyebutkan bahwa suhu air untuk pertumbuhan panjang, selera makan dan berat ikan koi berada pada $25^{\circ} \mathrm{C}-27^{\circ} \mathrm{C}$. Dimana dalam penelitiannya didapatkan tingginya suhu air dapat mengakibatkan pertumbuhan ikan menjadi lambat. Hal ini disebabkan suhu sangat berpengaruh terhadap proses metabolisme, dan proses metabolisme akan berpengauh terhadap pertumbuhan ikan.

Dari permasalahan tersebut, diperlukan suatu teknologi untuk memantau dan mengatur suhu air kolam secara otomatis melalui internet. Guna mendukung media pemeliharaan benih ikan koi tersebut, diperlukan pengembangan budidaya secara intensif yang dilakukan pada lingkungan terkontrol berbasis teknologi. Saat ini teknologi yang memungkinan untuk itu adalah dengan memanfaatkan Internet of Things (IoT). IoT adalah interkoneksi perangkat yang memiliki kemampuan berbagi informasi untuk berbagai aplikasi inovatif [3] .

Beberapa penelitian terkait monitoring suhu ikan koi telah dilakukan seperti pada [4], [5], dan [6] dengan menggunakan development board dari arduino, namun masih berfokus pada lingkungan untuk ikan koi dewasa. Untuk itu pada penelitian ini dirancang dan dibuat sistem monitoring suhu pada kolam benih ikan koi berbasis IoT.

\section{Metode Penelitian}

Tahapan pada penelitian ini dapat dilihat pada flowchart Gambar 1.

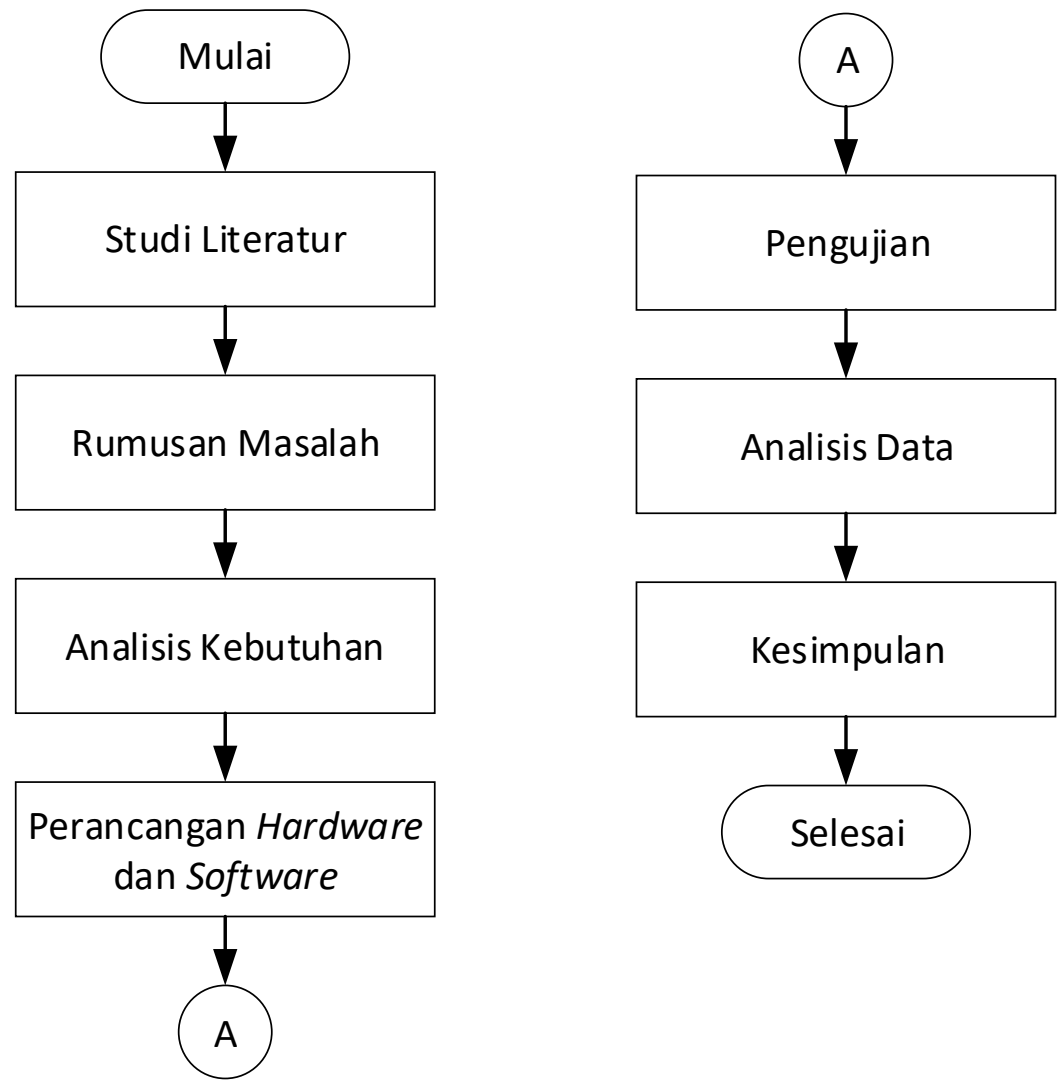

Gambar 1 Flowchart penelitian. 
Alur penelitian ini diawali dari studi literatur, tahap ini dilakukan pengumpulan data referensi dari jurnal maupun buku yang berkaitan dengan penelitian. Rumusan Masalah berisi mengenai identifikasi dari sebuah masalah. Analisis kebutuhan terdiri dari kebutuhan hardware dan software yang akan digunakan pada penelitian ini. Perancangan hardware dilakukan untuk mempermudah tahapan proses yang dilakukan. Perancangan software dilakukan dengan pembuatan flowchart program yang berisi tahapan urutan program yang berjalan. Selanjutnya tahap pengujian untuk mengetahui apakah dapat berfungsi dengan baik. Tahap analisis data untuk mendapatkan data-data yang diperoleh dari sistem dan dianalisis setelah melakukan pengujian. Tahapan terakhir yaitu kesimpulan dari hasil pengujian.

\subsection{Perancangan Hardware}

\subsubsection{Blok Diagram Sistem}

Sistem yang dibuat menggunakan development board NodeMCU dengan mikrokontroler ESP8266 [7] dengan spesifikasi teknis [8], dimana board ini digunakan untuk menerima data sensor suhu DS18B20 [9]. Kemudian sebagai output, board ini mengendalikan relay untuk menghidup-matikan heater. Ketika sensor suhu mendeteksi suhu dibawah normal yaitu kurang dari 25 derajat celcius maka heater akan ON, tapi ketika sensor suhu mendeteksi suhu atas normal yaitu lebih dari 27 derajat celcius maka otomatis heater akan OFF. Data suhu yang didapatkan akan dikirim ke platform Thingspeak melalui jalur internet agar kondisi suhu pada kolam budidaya dapat dimonitor secara langsung oleh user.

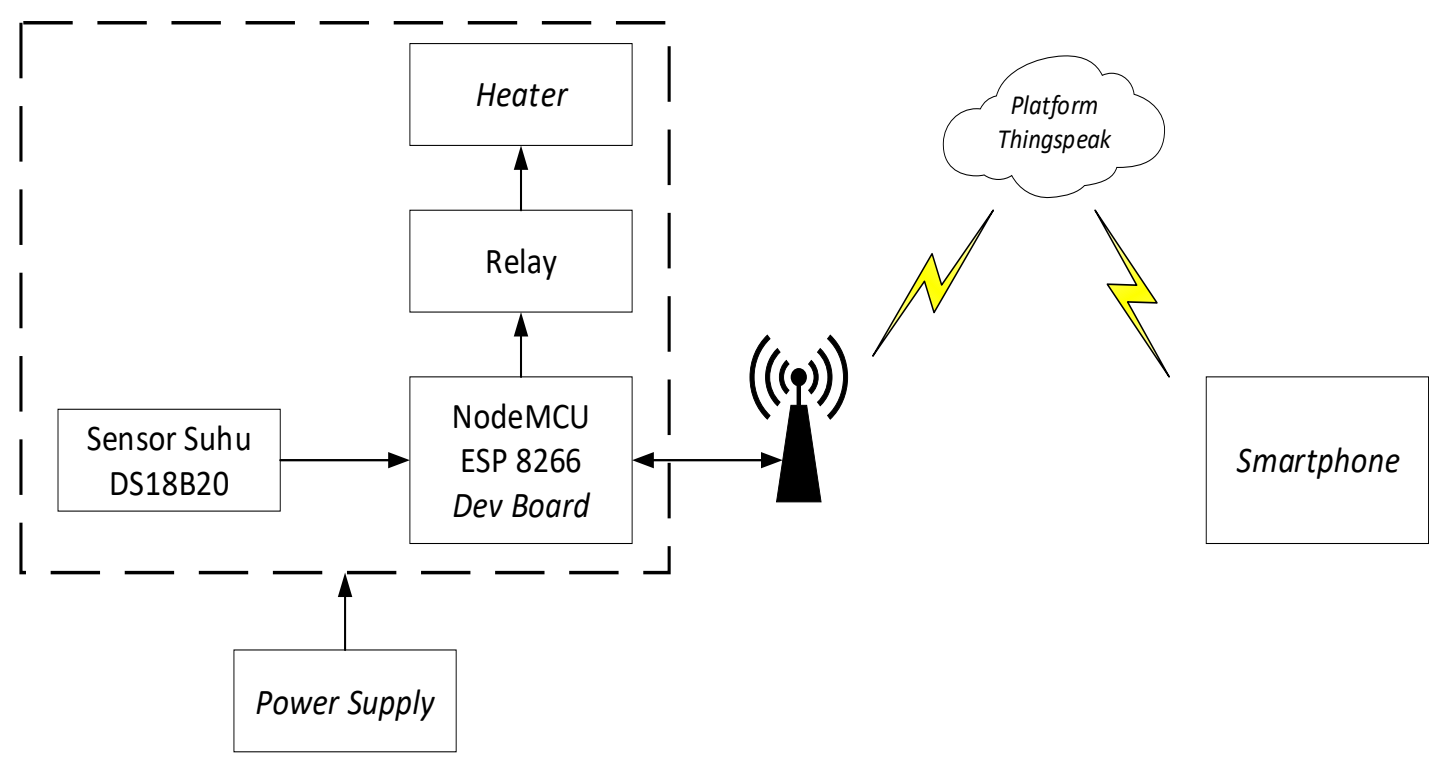

Gambar 2. Blok diagram sistem.

\subsubsection{Rangkaian Sistem}

Sistem yang dirancang terdiri dari NodeMCU ESP8266, sensor suhu DS18B20, relay 1 channel, heater, dan catu daya. Gambar 3 menunjukkan rangkaian dari sistem yang dibuat. Sensor DS18B20 adalah komponen yang berfungsi untuk mendeteksi suhu air kolam ikan koi agar suhu dapat terpantau setiap waktu. Sensor menggunakan resistor pull-up sebesar $4,7 \mathrm{k} \Omega$ yang dihubungkan pada VCC dan signal agar nilai suhu dapat terbaca dengan baik. 


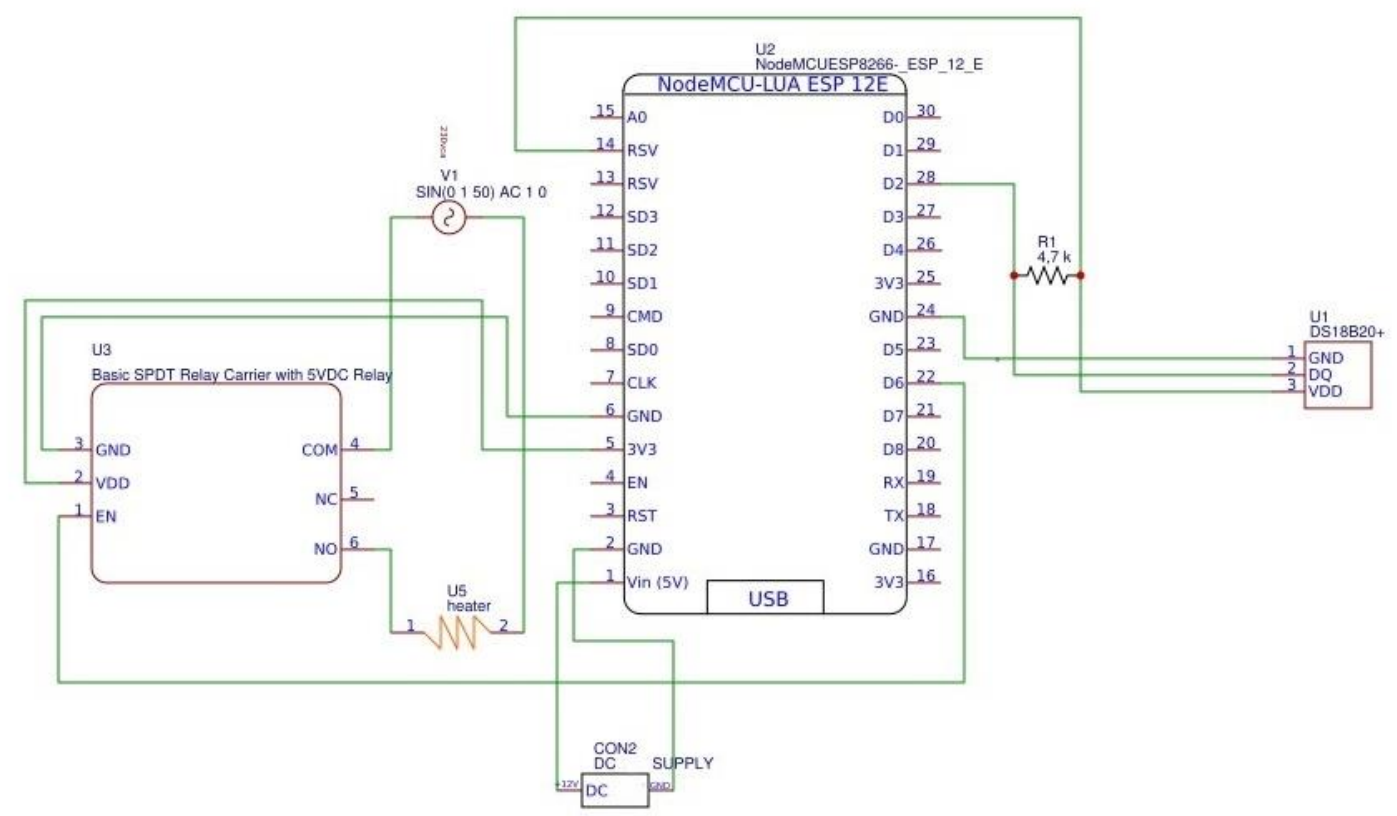

Gambar 3. Rangkaian sistem.

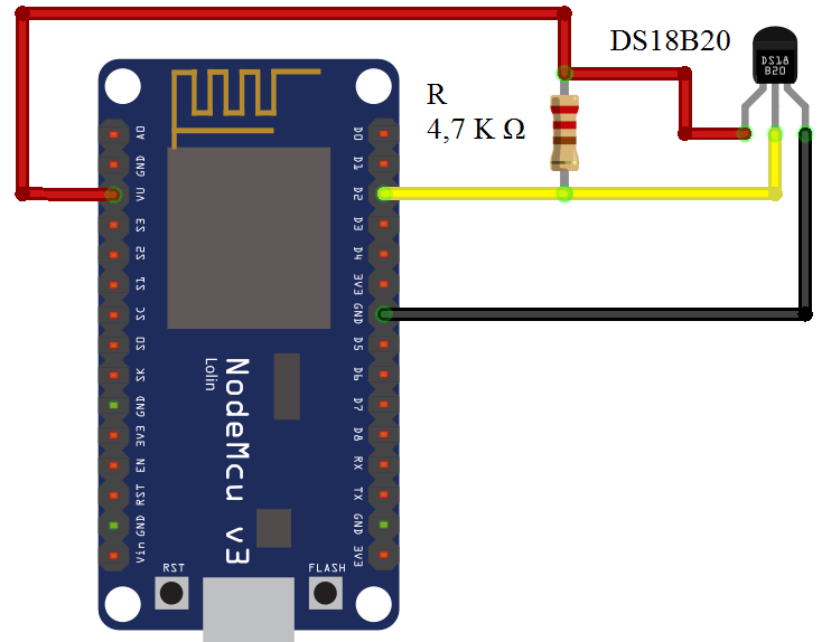

Gambar 4. Koneksi pin NodeMCU dengan sensor DS18B20.

Koneksi pin antara NodeMCU dengan sensor DS18B20 yang ditunjukan oleh Gambar 4, dapat dilihat penjelasanya pada Tabel 1 berikut :

Tabel 1. Koneksi pin NodeMCU dengan sensor.

\begin{tabular}{cc}
\hline PIN & Fungsi \\
\hline D2 & Pembacaan Sensor di Port D2 \\
VCC & Catu Daya Sensor 5V \\
GND & Grounding \\
\hline
\end{tabular}

Relay digunakan sebagai saklar otomatis yang menghubungkan antara mikrokontroler dengan heater. Relay akan menyambung atau memutus suplai tegangan dari heater sesuai dengan perintah dari mikrokontroler. Pada sistem ini, jika suhu terdeteksi kurang dari 25 derajat celcius maka relay akan menghidupkan heater dan jika suhu terdeteksi lebih dari 27 derajat celcius maka relay akan mematikan heater secara otomatis. 


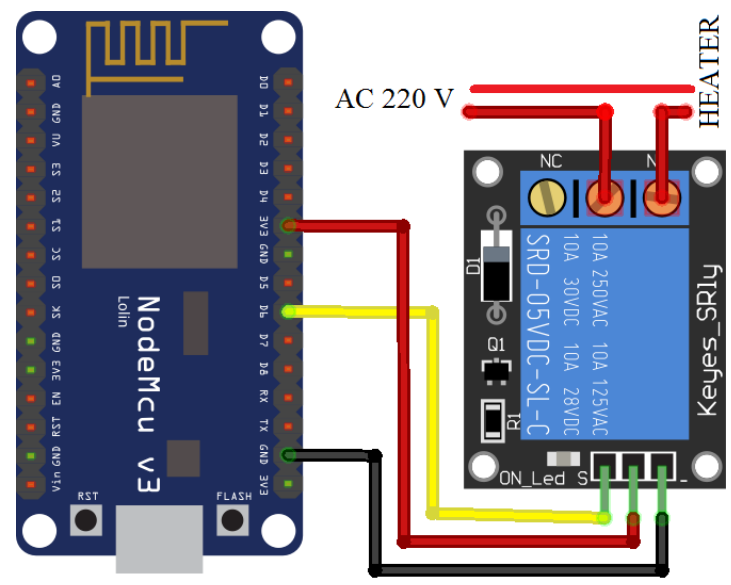

Gambar 5. Koneksi pin NodeMCU dengan relay.

Koneksi pin antara NodeMCU dengan Relay yang ditunjukan oleh Gambar 5, dapat dilihat penjelasanya pada Tabel 2 berikut.

Tabel 2. Koneksi NodeMCU dengan relay.

\begin{tabular}{cc}
\hline PIN & Fungsi \\
\hline D6 & Pembacaan Relay di Port D6 \\
VCC & Catu daya 3v \\
GND & Grounding \\
\hline
\end{tabular}

\subsection{Perancangan Software}

Flowchart program dari sistem yang dibuat ditunjukkan pada Gambar 6 berikut ini.
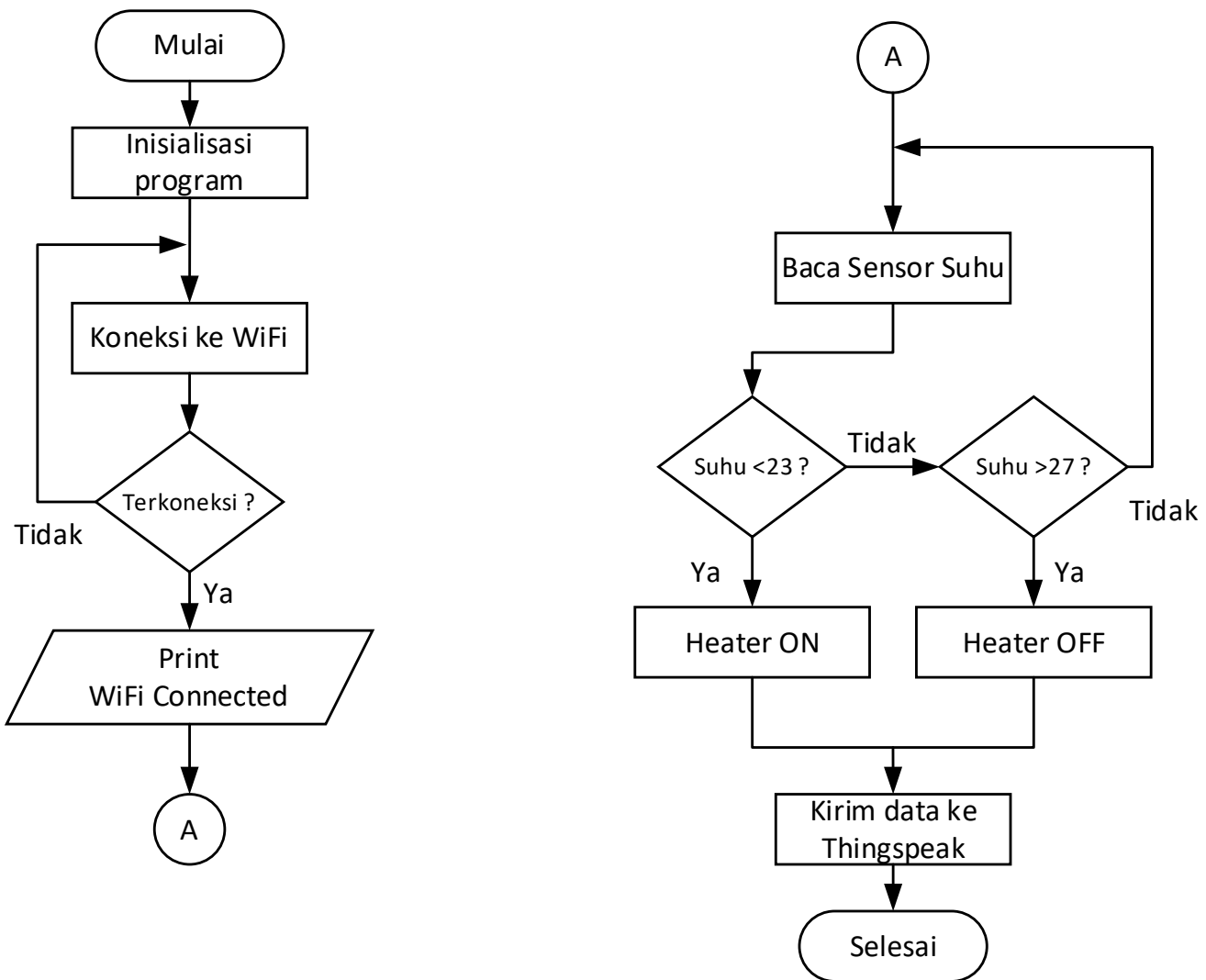

Gambar 6. Flowchart program. 
Tahapan pertama yang dilakukan yaitu inisialisasi program dan library yang digunakan. Selanjutnya akan melakukan koneksi ke jaringan WiFi yang sudah di set nama SSID dan password nya, jika terkoneksi dengan jaringan WiFi maka akan menuju langkah berikutnya. Setelah itu dilakukan pembacaan sensor suhu DS18b20, jika suhu terbaca kurang dari $25^{\circ} \mathrm{C}$ maka Heater akan ON, jika suhu terbaca lebih dari $27^{\circ} \mathrm{C}$ maka Heater OFF. Langkah terakhir data akan dikirimkan ke platform Thingspeak dan user dapat memantau data melalui smartphone.

\subsection{Skenario Pengujian}

Skenario pengujian sensor suhu DS18B20 bertujuan untuk mengetahui tingkat akurasi dan error dari data hasil pengukuran sensor suhu. Pengukuran dilakukan dengan cara menempatkan sensor suhu DS18B20 dan termometer pada kolam ikan koi dan membandingkan hasilnya. Pengukuran dilakukan dengan menggunakan 3 kondisi air yang berbeda yaitu air dingin dibawah 25 derajat celcius, air normal dengan rentang suhu antara 25 sampai 27 derajat celcius. Data pengukuran suhu menggunakan sensor akan tampil pada smartphone dan hasil pembacaan sensor suhu dicatat pada tabel. Pengujian sensor bertujuan menghitung tingkat error atau kesalahan.

Ragam ralat dari pengukuran atau pengamatan dibagi menjadi 3 macam, yaitu: ralat sistematis (systematic error), ralat rambang (random error), dan ralat kekeliruan tindakan. Ralat sistematis adalah ralat pengukuran yang akan memberikan efek tetap terhadap hasil ukur. Rumus perhitungan nilai error:

$$
\begin{gathered}
\text { error }=|X-X i|, \\
\% \text { error }=\left|\frac{(X-X i)}{X} x 100 \%\right|,
\end{gathered}
$$

dengan $X$ adalah data sebenarnya, $X i$ adalah data terukur, dan error adalah ralat systematic.

\section{Hasil dan Pembahasan}

\subsection{Implementasi Sistem}

\subsubsection{Implementasi Hardware}

Berikut adalah hasil implementasi dari sistem yang dirancang. Kolam yang digunakan pada pengujian ini yaitu akuarium mini berbentuk oval.

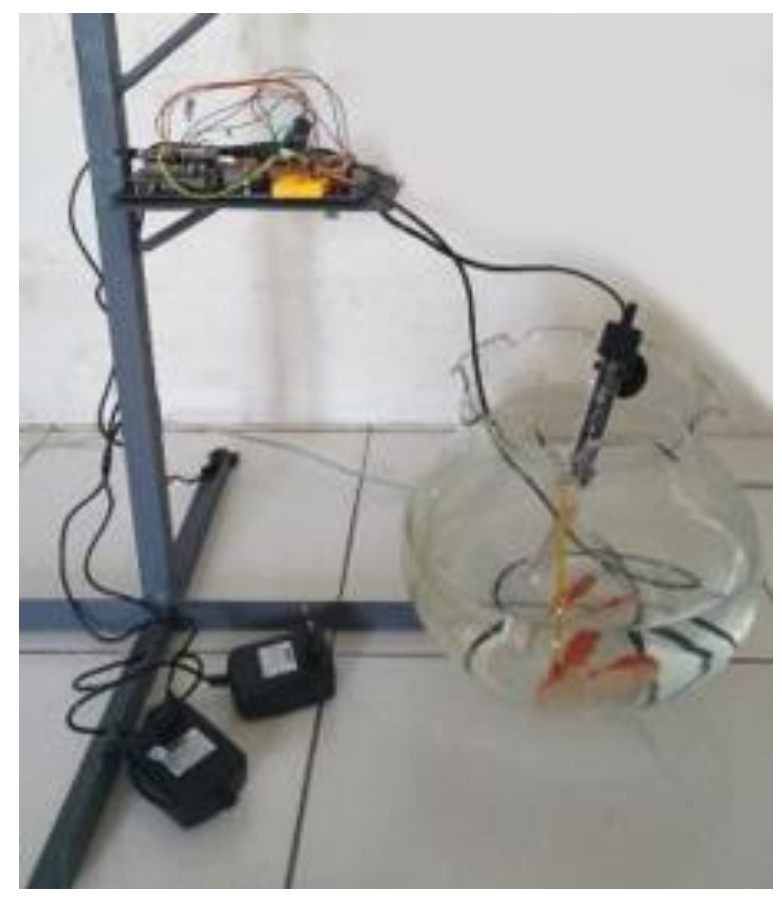

Gambar 7. Implementasi hardware. 


\subsubsection{Implementasi Software}

Bagian ini membahas bagaimana tampilan data nilai suhu kolam ikan koi dari NodeMCU menggunakan Thingspeak platform. Gambar 8 menunjukkan tampilan web pada Thingspeak platform, dapat dilihat bahwa channel yang dibuat pada web thingspeak sudah dapat menampilkan nilai suhu dalam bentuk grafik. Gambar 9 menunjukkan tampilan Thingspeak pada aplikasi android. Untuk memudahkan monitoring pada sisi user, maka tampilan pada thingspeak platform tersebut dibuat pada aplikasi android.

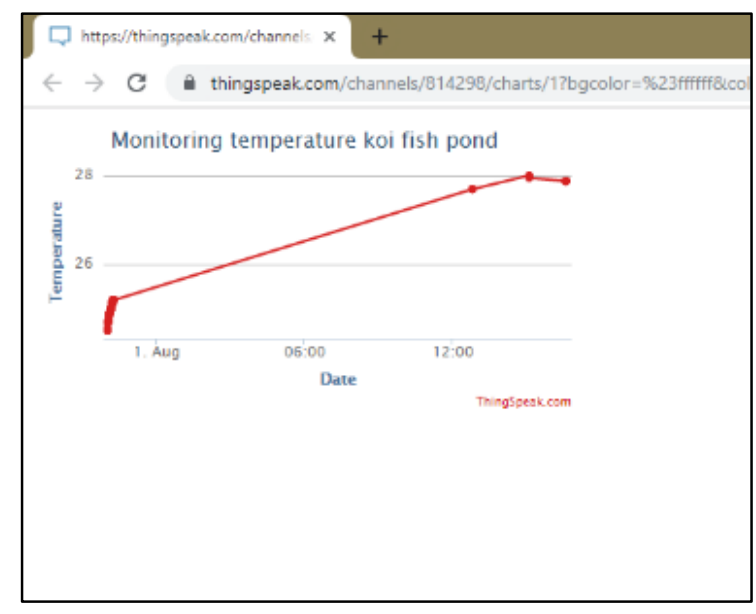

Gambar 8. Tampilan web platform thingspeak.

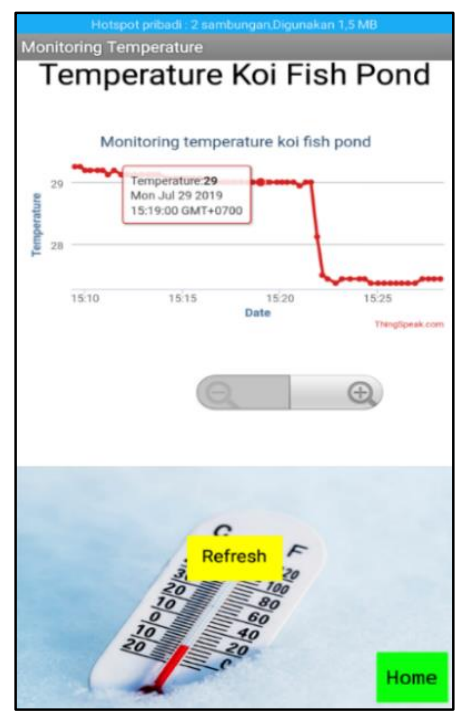

Gambar 9. Tampilan pada aplikasi andoid.

\subsection{Pengujian Sistem}

Pengujian dilakukan dengan mengambil data pengukuran sensor suhu DS18B20, sebagai pembanding digunakan termometer suhu air. Terdapat tiga pengujian yaitu saat kondisi dingin dengan suhu kurang dari $25^{\circ}$ celcius, kondisi normal dengan suhu $25^{\circ}-27^{0}$ celcius, dan kondisi panas dengan suhu diatas $27^{\circ}$ celcius. Setelah diuji kemudian dihitung nilai error dan persen error dari pembacaan sensor suhu dan termometer.

\subsubsection{Suhu Dingin $<25^{\circ} \mathrm{C}$}

Pengujian pengukuran suhu dingin dilakukan sebanyak 10 kali percobaan dan termometer digunakan sebagai pembanding hasil pengukuran Sensor DS18B20. Data hasil pengukuran dapat dilihat pada Tabel 3 .

Tabel 3. Hasil pengujian suhu pada kondisi dingin.

\begin{tabular}{ccccc}
\hline $\begin{array}{c}\text { Pengujian } \\
\text { Ke- }\end{array}$ & $\begin{array}{c}\text { Termometer } \\
\left({ }^{\circ} \mathbf{C}\right)\end{array}$ & $\begin{array}{c}\text { Sensor Suhu DS18B20 } \\
\left({ }^{\circ} \mathbf{C}\right)\end{array}$ & Error & \% Error \\
\hline 1 & 12 & 11.12 & 0.88 & 7.3 \\
2 & 14 & 12.75 & 1.25 & 8.9 \\
3 & 14 & 13.44 & 0.56 & 4 \\
4 & 15 & 14.5 & 0.5 & 3.3 \\
5 & 15 & 14.38 & 0.62 & 4.1 \\
6 & 16 & 15.75 & 0.25 & 1.5 \\
7 & 17 & 16.56 & 0.44 & 2.6 \\
8 & 17 & 16.87 & 0.13 & 0.76 \\
9 & 17 & 17.31 & 0.31 & 1.8 \\
10 & 18 & 18 & 0 & 0 \\
\hline \multicolumn{5}{c}{ Rata-rata error dan \% error } \\
\hline
\end{tabular}




\subsubsection{Suhu Normal $25^{\circ} \mathrm{C}-27^{\circ} \mathrm{C}$}

Pada pengujian suhu normal dilakukan 10 kali percobaan pengukuran. Hasil pengukuran menggunakan termometer sebagai pembanding akurasi dan hasil pengukuran Sensor DS18B20. Data hasil pengukuran dapat dilihat pada Tabel 4.

Tabel 4. Hasil pengujian suhu pada kondisi normal.

\begin{tabular}{ccccc}
\hline $\begin{array}{c}\text { Pengukuran } \\
\text { Ke }\end{array}$ & $\begin{array}{c}\text { Termometer } \\
\left({ }^{\mathbf{}} \mathbf{C}\right)\end{array}$ & $\begin{array}{c}\text { Sensor Suhu DS18B20 } \\
\left({ }^{\mathbf{0}}\right)\end{array}$ & Error & \% Error \\
\hline 1 & 25 & 24 & 1 & 4 \\
2 & 25 & 24,31 & 0,69 & 2,7 \\
3 & 25 & 24,37 & 0,63 & 2,5 \\
4 & 25 & 24,56 & 0,44 & 1,7 \\
5 & 25 & 24,69 & 0,31 & 1,2 \\
6 & 25 & 24,75 & 0,25 & 1 \\
7 & 25 & 24,81 & 0,19 & 0,76 \\
8 & 25 & 24,87 & 0,13 & 0,52 \\
9 & 25 & 25 & 0 & 0 \\
10 & 26 & 25,12 & 0,88 & 3,4 \\
\hline \multicolumn{5}{c}{} \\
\hline
\end{tabular}

\subsubsection{Suhu Panas $>27^{0} \mathrm{C}$}

Pada pengujian suhu panas dilakukan 10 kali percobaan pengukuran. Hasil pengukuran menggunakan termometer sebagai pembanding akurasi dan hasil pengukuran Sensor DS18B20. Data hasil pengukuran dapat dilihat pada Tabel 5.

Tabel 5. Hasil pengujian pada suhu panas.

\begin{tabular}{|c|c|c|c|c|}
\hline $\begin{array}{c}\text { Pengukuran } \\
\text { Ke }\end{array}$ & $\begin{array}{c}\text { Termometer ( } \\
\left.{ }^{\circ} \mathbf{C}\right)\end{array}$ & $\begin{array}{c}\text { Sensor Suhu DS18B20 ( } \\
\left.{ }^{\circ} \mathrm{C}\right)\end{array}$ & Error & $\%$ Error \\
\hline 1 & 37 & 37,25 & 0,25 & 0,67 \\
\hline 2 & 37 & 35,94 & 1,06 & 2,8 \\
\hline 3 & 37 & 36,5 & 0,5 & 1,3 \\
\hline 4 & 37 & 36,38 & 0,62 & 1,6 \\
\hline 5 & 37 & 36,13 & 0,87 & 2,3 \\
\hline 6 & 36 & 35,75 & 0,25 & 0,69 \\
\hline 7 & 36 & 35,63 & 0,37 & 1 \\
\hline 8 & 36 & 35,56 & 0,44 & 1,2 \\
\hline 9 & 36 & 35,38 & 0,62 & 1,7 \\
\hline 10 & 36 & 35,19 & 0,81 & 2,2 \\
\hline \multicolumn{3}{|c|}{ Rata-rata error dan \% error } & 0,579 & 1,546 \\
\hline
\end{tabular}

\subsection{Perhitungan Error}

Hasil pengujian pengukuran sensor suhu DS18B20 dengan pembanding termometer air hasilnya pada tabel. Sensor suhu DS18B20 digunakan untuk memonitoring suhu kolam ikan koi telah berfungsi dengan baik, terbukti dari hasil pengujian pada sensor suhu DS18B20 didapatkan tingkat rata-rata error pada kondisi dingin sebesar $0,49^{\circ} \mathrm{C}$, tingkat rata-rata error pada kondisi normal sebesar $0,45^{\circ} \mathrm{C}$ dan tingkat rata-rata error pada kondisi panas sebesar $0,57^{\circ} \mathrm{C}$ yang berarti tingkat akurasi pengukuran sensor ketika dibandingkan dengan termometer air tidak terlalu jauh. Sensor suhu DS18B20 memiliki akurasi baik.

Berikut perhitungan matematis rata-rata error. Diketahui :

a. Nilai error kondisi dingin $(0,88 ; 1,25 ; 0,56 ; 0,5 ; 0,62 ; 0,25 ; 0,44 ; 0,13 ; 0,31 ; 0)$

b. Nilai error kondisi normal $(1 ; 0,69 ; 0,63 ; 0,44 ; 0,31 ; 0,25 ; 0,19 ; 0,13 ; 0 ; 0 ; 88)$

c. Nilai error kondisi panas $(0,25 ; 1,06 ; 0,5 ; 0,62 ; 0,87 ; 0,25 ; 0,37 ; 0,44 ; 0,62 ; 0,81)$ 
Dengan menggunakan persamaan (1) dan (2) diatas, maka dapat dihitung nilai rata-rata dari error yang terjadi.

a. rata-rata error kondisi dingin

$$
\begin{aligned}
& =\frac{(d 1+d 3+d 3+\cdots . d n)}{\text { banyak data }} \\
& =\frac{(0,88+1,25+0,56+0,5+0,62+0,25+0,44+0,13+0,31+0)}{10} \\
& =\frac{(4,94)}{10} \\
& =0,494
\end{aligned}
$$

b. rata-rata error kondisi normal

$$
\begin{aligned}
& =\frac{(d 1+d 3+d 3+\cdots . d n)}{\text { banyak data }} \\
& =\frac{(1+0,69+0,63+0,44+0,31+0,25+0,19+0,13+0+0,88)}{10} \\
& =\frac{(4,52)}{10 .} \\
& =0,452
\end{aligned}
$$

c. rata - rata error kondisi panas

$$
\begin{aligned}
& =\frac{(d 1+d 3+d 3+\cdots \cdot d n)}{\text { banyak data }} \\
& =\frac{(0,25+1,06+0,5+0,62+0,87+0,25+0,37+0,44+0,62+0,81)}{10} \\
& =\frac{(5,79)}{10} \\
& =0,579
\end{aligned}
$$

\section{Kesimpulan}

Berdasarkan pengujian dan pembahasan yang telah dilakukan secara keseluruhan pada penelitian ini dapat diperoleh kesimpulan bahwa sistem yang dibuat telah berfungsi dengan baik untuk memantau suhu kolam benih ikan koi dan menstabilkan suhu kolam secara otomatis. Jika suhu dibawah normal $<25^{\circ} \mathrm{C}$ maka heater akan menyala untuk memanaskan kolam dan jika sudah pada suhu ideal $27^{\circ} \mathrm{C}$ maka heater otomatis mati. Hasil pengujian sensor suhu DS18B20 berfungsi dengan baik, termometer air digunakan sebagai pembanding dari pembacaan sensor. Dari hasil pengujian sensor suhu yang digunakan didapatkan rata-rata error pada kondisi dingin sebesar $3,426 \%$, rata-rata error pada kondisi normal sebesar $1,778 \%$ dan rata-rata error pada kondisi panas sebesar $1,546 \%$. Hal ini menunjukkan akurasi pengukuran sensor ketika dibandingkan dengan termometer air tidak terlalu jauh, sehingga sensor suhu DS18B20 memiliki akurasi baik.

\section{Referensi}

[1] E. Kusrini, S. Cindelaras, and A. B. Prasetio, "Pengembangan budidaya ikan hias koi (Cyprinus carpio) lokal di balai penelitian dan pengembangan budidaya ikan hias Depok," Media Akuakultur, vol 10, no 2, pp.71-78, 2015.

[2] Emaliana, S. Usman, and I. Lesmana, "Pengaruh perbedaan suhu terhadap pertumbuhan benih ikan mas koi (Cyprinus carpio)," Jurnal Aquacoastmarine, vol 4. No 3, 2016.

[3] J. Gubbi, R. Buyya, S. Marusic, and M. Palaniswami, "Internet of things (IoT): a vision, atchitectural, and future direction," Future Generation Computer Systems, vol 29, no 7, Feb., pp. 1645-1660, 2013. 
[4] T. A. Siswanto, and M. A. Rony, "Aplikasi monitoring suhu air untuk budidaya ikan koi dengan menggunakan mikrokontroler arduino nano sensor suhu DS18B20 waterproof dan peltier TEC1-12706 pada dunia koi”, Skanika, vol 1, no 1, pp.40-46, 2018.

[5] Salomoan, "Prototipe alat pemberian pakan ikan koi otomatis dan alat penurun suhu air otomatis pada akuarium berbasis arduino mega 2560," Universitas Negeri Jakarta, 2018.

[6] D. N. Bagenda, and Anggi, "Sistem perawatan ikan koi di akuarium otomatis berbasis desktop dan arduino uno," STMIK LPKIA Bandung, 2017.

[7] Espressif Systems, "ESP8266EX," ESP8266EX datasheet, Version 6.4 [Revised April 2020].

[8] Espressif Systems, "ESP8266 Technical Reference," Technical Reference, Version 1.4 [August 2019].

[9] Dallas Semiconductor, "DS18B20 programmable resolution 1-wire digital thermometer," DS18B20 datasheet. 